\title{
Psychoanalysis of Ghulam Azam: A Person Alleged of War Crimes
}

\section{Muttaki Bin Kamal}

\section{Introduction}

Ghulam Azam is probably the most hated name after Mir Zafar ${ }^{1}$, in the history of Bangladesh. He is not only alleged of war crimes and collaboration during the liberation war of Bangladesh, rather he has become the symbol of collaboration. He was recently arrested and placed before the International War Crimes Tribunal in Bangladesh. In spite of Jamayate Islami's argument, it is undoubted and proved that Ghulam Azam ${ }^{2}$ was a collaborator and as for his collaboration with the party convicted of war crimes, he cannot refuse his involvement in it.

There is a big contradiction in his personality. There are no criminal charges filed against him other than the war crimes. He is an elderly politician doing politics since the British period. He held several important posts in the political arena. He is from a religious background and known as an Islamic Scholar around the world. He is also much known as an Islamic Politician ${ }^{3}$. Unlike the present day political leaders, he holds no scandals or convictions. His image is rather saintly to his followers ${ }^{4}$ and general people with strong Muslim mentality!

The people of Jamayate Islami use this advantage to defend him. In some conversations with some people of Jamayate Islami and with even some non-Jamayati general people I heard the argument that, "How can a person do all his crimes in a single year, while he did none in the rest of his life?" I felt the need to answer this question.

In this paper, I will try to analyze the psychology of Ghulam Azam behind doing war crimes in 1971. To do so, I will use his autobiography; "Jibone Ja Dekhlam" or "What I have seen in the life", the first part; where he described his own becoming.

\section{The analysis}

A single question will guide the analysis, why Ghulam Azam did the war crimes? From the point of view of Freudian Psychoanalysis; we can propose that; his ego failed to balance between his id and his super ego. In a simple language, his conscience failed to control his bestial lust. That means he did the crimes to fulfill his personal lusts or goals. For most of the crimes, it happens. But in the case of Ghulam Azam, this explanation cannot work.

Because, if he did those crimes for his personal benefits; that means if he did those from the drive of id; he would have continued to do crimes; or he would have done more crimes in the past. But there is no such evidence of doing so. Moreover most of the allegations against him are about plotting, mass murder, selective murder, guiding the junta in war crimes etc.

He did not lobby for a governmental post from the junta. Rather he organized the paramilitary agencies like Peace Committee, in order to help the junta. He was not an executor, rather the "mastermind" of the crimes $^{6}$. From the types of his crimes it appears that, there was not a direct involvement of id. Actions or crimes like looting, rape, taking bribes or working as a paid employee may have manifested the involvement of personal benefits or id.

If it is not the cause behind his crimes, then what actually is the cause?

We are left with two other psychic actor, ego and super ego. Ego is the balance between id and super ego. What is left for ego after id is cancelled is the Super Ego.

Super ego is the control over the lust and it is control and repression merely. It is logic and discipline at their peak. There is no possibility of compromise. It is considered as the saintly part of the mind.

\footnotetext{
${ }^{1}$ Mir Zafar was the traitor who betrayed Nawab Siraj Ud Doula; the last independent ruler of Bengal. For his treachery, Bengal lost its independence to the English East India Company.

${ }^{2} \mathrm{He}$ admitted it in the interview with Banglavision; see at: www.youtube.com/watch?v=Bvt4OMVc0Vg

${ }^{3}$ Found online from the UK based campaign page to defend Ghulam Azam; See at: ghulamazam.net/

${ }^{4}$ The People of Jamayate Islami

${ }^{5}$ Prof. Ghulam Azam; “Jibone Ja Dekhlam"; Kamiab Publications; Banglabazar, Dhaka; January 2002.

${ }^{6}$ Tanim Ahmed; Quoted the War Crimes Tribunal's statement in his report; bdnews24;18.02.2012; see at : http://bdnews24.com/bangladesh/2013/02/18/ghulam-azam-was-mastermind
} 
But it is saintly in respect of id. Without id, super ego is a martial law administrator with mere control and repression, no mercy, no hope, no pleasure. It exposes brutality then. Anything undisciplined, unethical according to its construct, anything out of the structure is a enemy to super ego. It tends to stop that by any means then.

This is actually what happened to Ghulam Azam. His background, orientation, mindset deemed his id and weakened his ego. He has super ego in charge - construct, control and repression.

We get clear evidences from his own writings about his early age. He was born in a strict Muslim family. Both of his father and grandfather; whose influence is the most in his life he claimed ${ }^{7}$; were Maulanas ${ }^{8}$ and rigorous practitioners of the religion.

His early age was designed by these two people. In his autobiography, we see less participation of Ghulam Azam himself in decision making about his own life and the control of his father and grandfather in it. Both of them very strictly maintained all the rules and regulations of Islam; from the most important one to the lightest; with the same rigorousness.

For example, his father threatened one of his uncle; on the occasion that his uncle shaved beard; that he will stop the allowance for the uncle's studies. After that incident, no male members of his family ever dared to shave beard ${ }^{9}$

Another time, his younger brother, Ghulam Muazzam, appealed to his father to wear pants instead of "pyzama" ${ }^{10 "}$ as it would be comfortable and not disturbing to the patients when he would go to inspect them. It happened when Ghulam Muazzam was studying in the Kalkata Medical Collage. Ghulam Azam's father replied; "If it is not possible to study in medical without wearing pants, then you do not need to study there at all ${ }^{11}$." He replied so as he thought pants couldn't be worn over the heel of the leg. Wearing cloths extended under the heel of the leg is reprehensible in Islam.

Keeping beard is not mandatory in Islam. It is encouraged but it is not a sin not to keep beard ${ }^{12}$. About wearing pants or wearing dresses under the heel line, is not that strict also. But the strictness of Ghulam Azam's father in this issue shows the rigorousness of their religious practice. It also shows the 'crave' of this family for what Ghulam Azam calls "an Islamic life", where a little diversion is considered as a sin. In a mixed culture like Bengali culture, it is not always possible for any of the religion to maintain this rate of performance. To live a life exactly like this, Ghulam Azam needed a "state or society of Muslims'; monotonous; where this kind of mixture is absent. His construct is this rigid.

Another example of his rigid construct is his opinion about sports. He sees sports as waste of time and claims that the sports professionals have to answer in front of the $\operatorname{God}^{13}$ !

In the long run in his life, the rigidity of his construct magnified. After the influence of "Jamayate Islami" and its guru "Moududi"; the construct reached its highest level. What Jamayate Islami gave him was the dream for the "state or society of Muslims". As Pakistan was established as a "Muslim state", Jamayat dreamt to make it an "ideal Muslim state' by their claim. So, Ghulam Azam was obsessed of this "Muslim state" and blatantly supported Pakistan and their army.

He also bore hatred towards Hindus from his childhood. In his writing, the Hindu economic oppression is described with importance. Hindus are considered as the prime enemies of the Muslim and the "Muslim State" in his mind.

It also started from his family. For instance, the home of his maternal parents was in Dhaka. He used to come to Dhaka every year. There were a lot of Hindu houses around the house of his maternal parents. But he never mingled with them as his family member did not ${ }^{14}$.

He discussed about the Hindu hierarchy in the economy several times. In his words at that time of his childhood, Hindus controlled everything, from shops to courts. It is also sensed in his writings that Hindus "polluted" all of these places.

\footnotetext{
${ }^{7}$ Ibid; pg-65

${ }^{8}$ Maulana: An Islamic Scholar.

${ }^{9}$ Ibid 74

${ }^{10}$ A pant like garment

${ }^{11}$ Ibid; pg-77

${ }^{12}$ There are levels of emphasizes from the Islamic Scholars about this issue. But in core, it is a "Sunnat"; means a practice of the Prophet (SM) and thus to followed; not a "Farj"; means a dictate from the God, which is not to be disobeyed.
}

${ }^{13}$ Ibid; pg-124

${ }^{14}$ Ibid; pg-36 
He considers the "Hindus" as cowardly, treacherous lowlifes, in his words. "it was not tough for the Hindus to accept the slavery under British. ${ }^{15}$ " For this reason; as he said; "the Muslims came under double slavery, political slavery of the British and economic slavery of the Hindus. ${ }^{16}$

In a person, super ego operates with two elements; first, the construct of a person and second, the enemy of that construct which the super ego punishes. In a person's psychology, the enemy is id.

When the unbalanced, hierarchic super ego of a person is exposed in reality, it seeks for a rigid construct and a real enemy. Without these two elements, super ego cannot be in hierarchic exposure.

Such a condition is seen before. Three most luminous example of this problem are:

1. Adolph Hitler: His construct was the "Arian Greatness" and his enemy was "the Jews"

2. Andreas Breivik: His construct was the "Nordic Greatness" and his enemy was "the Muslims"

3. Ghulam Azam: His construct was "the obsession of a ideal Muslim state" and his enemy were "the Hindus"

From the approach of Ghulam Azam in 1971; it is evident. His obsession for the "ideal Muslim state" was the rigid construct that his super ego needed. The "enemy" was the Hindus and for that time, the Hindu state "India". He claimed that he and his team was fighting against the "Indian Miscreants'. In his statements:

"India is interfering the internal affairs of East Pakistan. Wherever the patriotic Pakistanis find the Indian agents and infiltrators, they will destroy them ${ }^{17}$."

His obsession of Pakistan to be an "ideal Muslim state" is manifested in these words:

"May the god let the Pakistan army to be the true Muslim soldiers and defend the country, may he let us to be true Pakistanis and Muslims and make Pakistan the land of Islam forever ${ }^{18}$."

To defend his construct and destroy his enemy, Ghulam Azam's super ego drove him to the extent of war crimes. It is not like the other crimes that the criminals believe that his action is wrong. Rather, when he committed these crimes, Ghulam Azam believed that it was the right path. Even after the independence he repeated this claim ${ }^{19}$.

\section{Conclusion:}

Here it is, the cause behind the war crimes of Ghulam Azam; and that is the hierarchic manifestation of super ego. The common trend in Bangladesh of treating Ghulam Azam does not recognize this fact. It considers him as a common criminal, who did the war crimes to satisfy his id. But it is a wrong and deadly approach. This approach drives people to poke out misdeeds of him and even lie to support the trends claim and ignore the actual cause. As a result, contradiction arises. Even the international war crimes tribunal at present day is taking the same wrong approach I think. It is resulting in improper placement of evidences, lack of proper evidences, improper use of evidences and confusion about the whole trial process.

The criminals of hierarchic manifestation of super ego are often considered as right by the people. We saw the rise of Adolph Hitler and Nazis.

Even Ghulam Azam is very popular and respected as an Islamic scholar to the Muslim people of the country and their number is not little.

It is because control and rigidity are considered as virtues. These criminals show strength in these two sectors. So, the people cannot accept that they can do any crime. But the people do not consider that, the excess of control and rigidity can bring severe harm.

There were many evidences unexplored in this paper. But those evidences also indicate the role of super ego.

\section{Bibliography:}

[1]. Sheikh Hafizur Rahman Karzon; "Theoretical and Applied Criminology"; Palal Prakashoni; ELCOP; Dhaka

[2]. Prof. Ghulam Azam; "Jibone Ja Dekhlam"; Kamiab Publications; Banglabazar, Dhaka; January 2002.

[3]. Adolph Hitler;"Mein Kampf"; Translated by James Murphy; February 1939

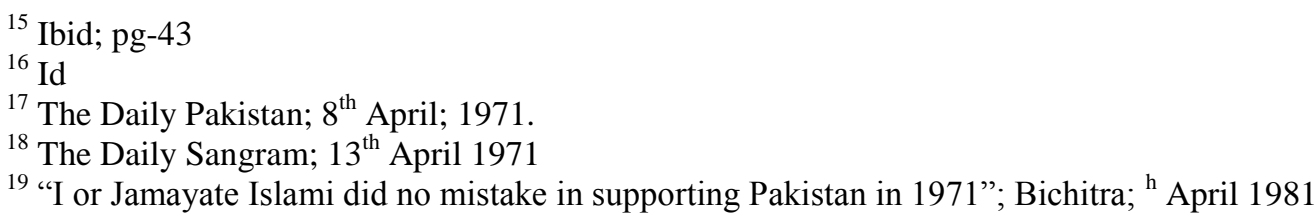

